\title{
The Exploration and Practice of Developing College Students' Innovative Ability on Multi-Platforms
}

\author{
Yuzhi Liu ${ }^{1, a}$, Jianpeng Bian ${ }^{2, b}$, Liqiang $\mathrm{Hu}^{3, \mathrm{c}}$ \\ ${ }^{1}$ Electrical and Electronic Engineering College, Shijiazhuang Tiedao University, Shijiazhuang, \\ 050043, China \\ ${ }^{2}$ Electrical and Electronic Engineering College, Shijiazhuang Tiedao University, Shijiazhuang, \\ 050043, China \\ ${ }^{3}$ Electrical and Electronic Engineering College, Shijiazhuang Tiedao University, Shijiazhuang, \\ 050043, China \\ aemail: lyz1997a@126.com, bemail: bjp210@126.com, 'email: hulq9802041@126.com
}

Keywords: Innovative Ability; Multi-platforms; Exploration and Practice

\begin{abstract}
At first the article analyzes the importance of college students' ability to innovate. Then it discusses the ways and methods of developing college students' innovation ability. At last, the paper summarizes the measures and fruits of cultivating college students' innovation ability on multi-platforms.
\end{abstract}

\section{Introduction}

Under the urgent requirement of upgrading the social economic transformation and comprehensively improving competitiveness, scientific and technological innovation has replaced natural resources and capital to become the core factors that determine the national and regional competitiveness. Hence cultivating various engineering talents with strong innovation ability and broad international vision has become the necessary choice to boost the core competitiveness of our country, construct new-type country and advance on the path of new industrialization. As an important channel to cultivate senior talents, higher education should take initiatives to adapt to the strategic demands of our country and undertake the responsibility to develop applied-type talents with great innovative abilities and solid basis in order to cope with the social development in the future. However, with constantly expanding of university students' scale, lots of problems appear in the college graduates cultivated by engineering schools. They are weak in the operation and professional knowledge. They are lacking the ability and experience to solve problems in reality as well. So it is difficult for them to meet the needs of enterprises.

The article explores the ways and methods for developing college students' innovative ability in combination with the professional characteristics of engineering schools. It also elaborates on the measures and fruits of different stages of cultivating college students' innovative ability.

\section{The importance of developing college students' innovative ability}

The senior creative talents are wanted by the whole society but will not appear abruptly. Whether a person can have the innovative ability is linked with living environment, especially his or her educational environment. Since the 21st century, the contradiction between the increasing number of graduates and the capacity of the society is increasing serious with universities students admitting on a larger scale. It is not unusual for graduates to be unemployed. In the meantime, the development of our country needs a large amount of human resources with deep scientific reserve and innovative ability. Enterprises and public institutions have fully realized the importance of talents, but they can do nothing about the severe competition of talents, they also have difficulties in recruiting talents. The shortage of senior talents with innovative ability and the unreasonable distribution structure of talents are serious, particularly in the aspect of lacking of the awareness of 
working hard. The key to solving the contradiction at the deeper level in cultivating senior talents and improving quality is to innovate and create the atmosphere of the environment.

On the other hand, in the current age with knowledge exploding and the rate of knowledge transformation quickening, the knowledge choice, integration, operation and transformation become more important compared to accepting knowledge. Therefore, college students should constantly strengthen their innovative consciousness and boost their innovative ability through participating in innovative training. Only in this way can they satisfy the social needs of knowledge economy and have great competitiveness in finding employment. Furthermore, they can constantly make their knowledge and ability structure perfect in later work and study, so as to continuously perfect themselves, to adapt and serve the society.

\section{The main methods and ways to develop the innovation ability of students}

In order to cultivate and improve students' innovative ability and their innovative ideas, training innovative ideas has three dimensions: activating the sense of innovation, establishing innovative ideas and developing innovation spirit. Everyone has the potential to innovate but cannot innovate. The main reason is that many people do not realize their innovative potential, not to mention more consciously cultivation.

Creating a favorable innovative condition and the environment. Innovation abilities are not innate; they acquire gradually learning and practice. The key to exploit students' creative potential and transform it into students' creative ability is to create favorable conditions and innovation campus atmosphere which mainly appear in the construction of campus culture, science and technology, carrying out extra-curricular activities, pushing the formation of innovative teachers and forming innovating science courses[2],such as organizing school competitions in various disciplines of knowledge, science and technology inventions game, holding the electronic design contests, carrying out the construction of campus culture, science and technology to create an atmosphere, guiding students to conduct scientific research and so on. Furthermore, teachers can also open school laboratories (for students to create an innovative environment), create innovative educational experiment base (for students to discuss, exchange, stimulate innovation spark place), provide research funding (for students' practical innovation to provide financial assurance) and doing other forms to make innovation be possible. Through school and enterprise resource sharing mode, the students can make the communication with others. School institutions can establish a stable teaching practice base for students and be fill with fresh blood.

The reasonable leading of teachers. Teachers play an essential role in improving the quality of higher education. To cultivate and improve students' innovative ability needs a teacher team which can do an innovative thinking, have ahead concepts and handle high quality and innovative skills. There are Boles in the world, and then there are thousand-kilometer horses. Such a teachers team can transform the "Cramming education, Centralized education" to "thematic discussion, case type" and other heuristics or innovative learning, which can promote the reformation of the system and personnel training mode of course. It can also establish and improve the innovation ability evaluation system. Through the variety of internal and external teaching lessons, the real work will be carried out. Teachers can help students put innovative ideas into innovative spirit, to deal with the rapid changes in society. 


\section{Test results}

Relying on electronic design and other competitions to create the environment for innovation. National Undergraduate Electronic Design Contest is one of the four disciplines of competition Ministry of Education advocate, which needs for students to participate in science and technology innovation contest. Electronic Design Contest has extremely practical significance to cultivate students' innovative abilities. First, the contest topic is interdisciplinary and integrated, it uses advanced equipment, training methods and tools that are advanced, scientific, systematic and integrated; second, the topics are closely combined with teaching practice, which base on the foundation and focus on front. In preparation and participation in the race, students should check the information, discuss programs, design circuit and do other work for the real problems. They should help foster innovation and collaborative spirit; third, the competition will attract and encourage the students to actively participate in extracurricular technological innovation activities. This will create conditions for innovative talents.

Reasonable arrangements for teaching practice, and digging out the innovation potential from college students. Practical teaching plays an irreplaceable role in the development of learning theoretical knowledge, cultivating practical ability of students and exploring the unknown[3]. To improve students' ability to innovate, teachers must emphasize on practical aspects. According to the characteristics of engineering school, teachers intentionally make more practical teaching efforts when they make training plans, such as adding 'signal identify the images and graphics' and 'object-oriented programming language' courses.

In addition, we can set up long-term engineering practice extracurricular lessons. Engineering Practice Course can be divided into basic training and engineering practice application stage. In basic training stage, teachers mainly focus on the basic engineering practical skills, learning and training, and pay more attention to building knowledge platform for innovative engineering practices; In engineering practical application stage, combining with professional and personal characteristics are important so that students turn simple imitation to individuals to create, from dependence to independence counseling design and projects are from passive acceptance to active discovery programs. It helps the individual innovation capability to leap.

Using classroom teaching, cultivate students' innovative ability. At present, Chinese college teaching is the traditional classroom teaching model, with the support of the teaching of language practice. In order to improve students' ability to innovate, the research group teachers work together to continually update and reform the existing teaching methods. Some teachers try to let students teach themselves, use symposia new forms of teaching and classroom debate. In this way, it not only stimulates the curiosity of students, but also improves the students' sense of responsibility. Through sharing functions, finding information, making the courseware, telling lectures and other processes, the students' ability of collaboration, creation, imagination, expression are improved. By exchanging different ideas, students get more time and opportunity to think. With the discovery of the problem, abilities of analyzing, innovation and solving problems are gradually developed. Innovative abilities are improving at the same time. Some teachers use CDIO teaching methods to integrate advantages with the "Fundamentals of Mono-Chip Computers\& Applications", "Computer graphics skills training" and "single-chip interface design" these three courses[4]. This method changes 'course' to 'product development'. Through based project learning, students truly experienced an electronic product development process. Through the process of independent design, drawing, options, welding and the debugging, the students can find shortcomings to arouse interesting in obtaining a sense of accomplishment. Their practical ability, the abilities to identify problems, problem-solving skills and innovation ability have been improved. The students generally thought they have learned the useful skills.

Reform of the teaching evaluation, pave the way for innovation. The 'examination-centered, knowledge-based mastery' academic performance evaluation methods cause students blindly pursuing test scores while ignoring the ability of other cultures. It is not lining with today's personnel training policy, it also may lead students to be in the high scores and low abilities 
situations. Reasonable teaching evaluation should take standards of value judgment[5]. It should tend to the innovation. The guiding ideology of the evaluation is 'knowledge-based, innovation as the goal'. Student evaluation is no longer papers formed by the blank, choose, literacy programs and other test questions, it is replaced by student self-designed 'works'. The circuit board layout decides "computer-aided drafting skills training" results; The works' functions, practical objects, appearances and reports decide "single-chip interface design" results; "Principles and Applications" results are based on situation of work and defense. This process can not only use evaluate methods to bound and regulate the students' learning process, but also a effective way to encourage students to train innovation abilities.

The phased objectives. Historical achievements have been got in the college students' innovation abilities by multi-platform cultivation. First, the teaching and evaluation methods CDIO are not only welcome by students, but also by peers and experts praise. The research group "SCM principles and related practice courses system Examination Reform exploration" "won the Grand Prize in Classroom Teaching event. Second, the open-practice training management model that base on practice teaching makes great teaching effect. Second-classroom activities are actively held, innovation performances are significant, there are six works won the prize in "Challenge Cup" in Hebei Province of Extracurricular Scientific Contest, 2 second prizes and 3 third prizes in the National University Students "Freescale Cup" Smart Car Contest North Division; 2 third prizes in National Undergraduate Electronic design Contest Hebei contest; 2 second prizes and 2 third prizes in the first robot Hebei Open. Gaining 1 national project and 7 provincial projects for the second batch of college students national innovation and entrepreneurship training program.

\section{Conclusion}

College Students Creative Ability is not isolated. It must run through the entire process of personnel training. Studies have shown that: cultivating concepts and methods for students' innovation abilities building on the multi-platform are advanced and feasible, especially suiting for all links and processions of teaching in engineering colleges, which help to cultivate an interest in learning the culture, arouse enthusiasm and enhance innovation capabilities.

\section{Acknowledgement}

In this paper, the research was sponsored by the Nature Science Foundation of Hebei Province (Project No. ZD2014091) and the Higher Education Reform Foundation of Hebei Province (Project No. 2012GJJG149, 2012GJJG084).

\section{References}

[1] Wei Zhang, Institutional guarantee to explore high-level innovative talents[J], China Higher Education, 2010(21):15-17.

[2] Xiaoru Wang, Biao Gao, Discussion on the mode of CDIO engineering education and training of innovation ability[J], Guide to Business, 2012(7):232-233

[3] Huadong Yu. Strengthen practical aspects to Develop College Students'Ability of Pioneering Patent [J], China Higher Education, 2013(2):72-75.

[4] Xiaoyan Deng, Jianhong Di, Yong Yang, Yuzhi Liu, Asuming in test method of the SCM curriculum [J],Curriculum Education Research, 2013(34):227-228.

[5] Yan Zhou, Min Zhou, Guo zhangJiang. Experiment teaching reform for industrial engineering majors based on CDIO [J]. Laboratory science, 2013(2):72-75. 